\title{
MÉTODOS DE REMOÇÃO DA SARCOTESTA NA GERMINAÇÃO DE SEMENTES DE JARACATIÁ ${ }^{1}$
}

\author{
Sílvio de Jesus Freitas², Deborah Guerra Barroso ${ }^{3}$, Roberto Ferreira da Silva ${ }^{4}$, Victor Hugo Caldas \\ Rodrigues Martins ${ }^{5}$, Marcela Duarte Schinke Freitas ${ }^{6}$ e Patrícia Ribeiro Ferreira ${ }^{7}$
}

\begin{abstract}
RESUMO - A presença da sarcotesta pode prejudicar a germinação e desenvolvimento das plântulas. O objetivo deste trabalho foi identificar métodos favoráveis à remoção da sarcotesta para a promoção da germinação de sementes de Jaracatia spinosa, cujas sementes foram submetidas aos seguintes tratamentos: 1- sem remoção da sarcotesta; 2- remoção com fricção sobre peneira, com adição de areia; 3- remoção com fricção sobre peneira com adição de cal; 4- remoção com o uso de liquidificador, 5- remoção com despolpador de sementes; e 6- remoção com solução química (imersão, por $30 \mathrm{~min}$, numa solução composta por $1.0 \mathrm{~L}$ de água, $3.5 \mathrm{~mL}$ de hipoclorito de sódio, $3.0 \mathrm{~mL}$ de ácido muriático e $22.5 \mathrm{~g}$ de soda cáustica), em que as sementes foram avaliadas quanto à percentagem de germinação, Índice de Velocidade de Emergência (IVE) e comprimento da parte aérea de plântulas. O método mais favorável à remoção da sarcotesta e promoção da germinação das sementes de jaracatiá foi a fricção sobre peneira com a adição de areia.
\end{abstract}

Palavras-chave: Jaracatia spinosa (Aubl.) A. DC, Sementes e Mucilagem.

\section{GERMINATION OF JARACATIÁ SEEDS SUBMITTED TO DIFFERENT METHODS OF SARCOTESTA REMOVAL}

\begin{abstract}
The objective of this work was to verify the effect of different removal methods of the sarcotesta of Jaracatia spinosa (Aubl.) A. DC. seeds on the germination percentage, (SGI) Speed of Germination Index and length of the aerial part. The seeds were submitted to the following treatments: 1 - without sarcotesta removal; 2 - removal with friction on sieve, with sand; 3 - removal with friction on sieve with whitewash; 4 - removal with blender, 5 - removal with seeds pulpremoval and 6 - removal with chemical solution (immersion, for 30 minutes, in solution for $1.0 \mathrm{~L}$ of water, $3.5 \mathrm{~mL}$ of sodium hypochlorite, $3.0 \mathrm{~mL}$ of muriatic acid and $22.5 \mathrm{~g}$ of caustic soda). The presence of the sarcotesta harms the seed germination and development. The best methods for the removal of the jaracatiá seeds sarcotesta are the friction on sieve with sand or whitewash.
\end{abstract}

Keywords: Jaracatia spinosa (Aubl.) A. DC, Seeds and Mucilage.

\section{INTRODUÇÃO}

O Jaracatia spinosa (Aubl.) A. DC. (jaracatiá) é uma espécie da família Caricaceae, decídua, eliófita, pioneira, característica dos solos férteis de fundo de vales e de planícies aluviais da floresta pluvial, que ocorre tanto no interior das matas primárias densas quanto em clareiras, beiras de matas e em formações secundárias em estágios adiantados da sucessão vegetal (CORREIA, 1984). É uma planta importante nas cadeias tróficas pela produção de frutos comestíveis (PAOLI, 1986) e apresenta potencial para cultivo, possibilitando a exploração do caule, frutos verdes e maduros e do látex.

\footnotetext{
${ }^{1}$ Recebido em 05.06.2008 e aceito para publicação em 25.08.2010.

${ }^{2}$ Pós-Doutorado em andamento pela Universidade Estadual do Norte Fluminense, UENF, Brasill. E-mail: < freitassj@yahoo.com.br > .

${ }^{3}$ Professora Associada da Universidade Estadual do Norte Fluminense, UENF, Brasil. E-mail: < deborah@uenf.br>.

${ }^{4}$ Professor Titular da Universidade Estadual do Norte Fluminense, UENF, Brasil. E-mail: <roberto@uenf.br>.

${ }^{5}$ Engenheiro Agrônomo pela Universidade Estadual do Norte Fluminense, UENF, Brasil. E-mail: <victorhcaldas@hotmail.com>.

${ }^{6}$ Bióloga pela Universidade Salgado Filho, Brasil. E-mail: < freitasmadu@hotmail.com>.

${ }^{7}$ Técnica de Laboratório de Nível Médio, Universidade Estadual do Norte Fluminense, Brasil.E-mail: <patrícia_uenfbio@hotmail.com>.
} 
Ocorre no Brasil desde o Sul da Bahia até o Rio Grande do Sul, passando por Minas Gerais, Goiás e Mato Grosso do Sul (LORENZI, 2002). A espécie é de interesse para o melhoramento genético do mamão (Carica papaya L.), podendo contribuir para sua produtividade ou como fonte de resistência ao vírus do mosaico (EDER-SILVA et al., 2007).

Essa espécie, no entanto, está em risco de extinção em virtude, provavelmente, do fato de a indústria de doces caseiros usar partes do seu caule em substituição à polpa do fruto de coco. Hoje, o jaracatiá é encontrado nas fazendas tradicionais, onde a vegetação nativa foi preservada, ou nos viveiros de alguns centros de pesquisa, sendo importantes estudos para viabilizar sua propagação e a conservação de material genético.

A principal forma de propagação do jaracatiá ocorre por meio de sementes, sendo extremamente importante o estudo dos fatores que influenciam a germinação e desenvolvimento das mudas.

A sarcotesta é material gelatinoso que protege a semente, podendo vir a comprometer a germinação, tornando-a lenta e desuniforme, bem como acarretar desenvolvimento heterogêneo das plântulas no viveiro (MARIN et al., 1987). Isso aumenta os cuidados e o custo de produção das mudas, que tardam a se desenvolver e ficam por mais tempo expostas a pragas, microrganismos e à competição com plantas daninhas.

A presença da sarcotesta pode influenciar a germinação e desenvolvimento de sementes de algumas espécies, como mamão (GHERARDI e VALIO; 1976; REYES et al., 1980; CHOW e LIN, 1991; SCHMILDT et al., 1993; TOKUHISA et al., 2007; TOKUHISA et al., 2008), café (SALES et al., 2001; ARAUJO et al., 2004), maracujá (MELO, 1996; CONEGLIAN et al., 2000; FERREIRA et al., 2005) e Copaifera langsdorffii Desf. (VILELA, 1993; PEREIRA et al., 2007; PEREIRA et al., 2009). Essa inibição se deve à presença de substâncias inibidoras, também observadas em Piptodenio macrocarpo Benth., Joannesia princeps Vell. e Balbergia nigra Vell. (MARCIEL et al., 1992) e Michelia champaca L. (CONDIANI et al., 2004).

As sementes das diferentes espécies apresentam mucilagem com características químicas e estruturais próprias e, dessa forma, é necessário determinar o método físico ou químico mais eficiente para cada caso. Segundo Medina (1989), a remoção da sarcotesta pode ser feita à mão, ou por outros métodos físicos, como fricção das sementes com areia contra a malha fina de uma peneira sob jato de água corrente, ou com a utilização cuidadosa de liquidificador em baixa rotação, ligando e desligando repetidamente por curto espaço de tempo. São também utilizados métodos químicos, que consistem no uso de substâncias ou reagentes. Dias (1993), avaliando a eficiência de diferentes tipos de remoção da mucilagem (degomagem) na qualidade de sementes de café, concluiu que a degomagem, realizada por meio de métodos naturais (fermentação) ou químicos (com utilização de hidróxido de sódio), não afetam a qualidade fisiológica das sementes, e o processo químico apresenta como vantagem a rapidez com que a operação pode ser realizada, ou seja, em menos de 10 min em vez das 24 h necessárias para a fermentação natural.

O objetivo deste trabalho foi identificar métodos favoráveis à remoção da sarcotesta para a promoção da germinação de sementes de Jaracatia spinosa.

\section{MATÉRIAL E MÉTODOS}

Este trabalho foi realizado no Laboratório de Fitotecnia no Setor de Silvicultura da Universidade Estadual do Norte Fluminense Darcy Ribeiro, em Campos dos Goytacazes, RJ.

Foram colhidos 20 frutos de jaracatiá em oito plantas-mãe na cidade mineira de Belo Oriente, situada a $21^{\circ} 57^{\prime} 30^{\prime \prime}$ S e $42^{\circ} 00^{\prime} 48^{\prime \prime} \mathrm{W}$, com altitude média de $632 \mathrm{~m}$, temperatura média de $25^{\circ} \mathrm{C}$ e com pluviosidade média de $1.400 \mathrm{~mm}$.

Os frutos apresentavam 100\% da superficie externa com coloração amarelada, tendo em média 6,18 cm de comprimento, 4,12 cm de diâmetro, 1,0 cm de espesura de polpa, com peso de 68,27 g apresentando 140 sementes por fruto.

As sementes foram retiradas com o auxílio de uma espátula, homogeneizadas e lavadas com água para a remoção da placenta e de restos de polpa. Em seguida, essas foram separadas em seis porções, que receberam os seguintes tratamentos: 1- sem remoção da sarcotesta (testemunha); 2- remoção com fricção sobre peneira, com adição de areia; 3- remoção com fricção sobre peneira com adição de cal; 4- remoção com liquidificador, 5remoção com despolpador de sementes; e 6- remoção com solução química. 
Durante a retirada das sementes por fricção contra a malha de peneira com adição de areia ou cal (tratamentos 2 e 3), a peneira permaneceu sob uma torneira com jato de água corrente, sendo a areia e a cal colocadas juntas com as sementes, e a mistura foi levemente friccionada contra a malha da peneira até a remoção da sarcotesta.

Nos tratamentos 4 e 5, as sementes foram misturadas com quantidade de água equivalente a três vezes o seu volume. No tratamento 4, a hélice do liquidificador foi revestida com borracha (garrote) para evitar danos às sementes e acionada por 1 min, com rotação mínima. O despolpador é um liquidificador adaptado que apresenta disco com perfurações no lugar da hélice e é acionado por 4 min na rotação mínima (tratamento 5).

Na remoção química da sarcotesta (tratamento 6), as sementes foram imersas, por $30 \mathrm{~min}$, em uma solução composta por 1,0 L de água, 3,5 mL de hipoclorito de sódio, 3,0 mL de ácido muriático e 22,5 g de soda cáustica e, em seguida, lavadas em água corrente.

Após as operações de remoção da sarcotesta, retiraram-se de cada tratamento 100 sementes para a determinação da porcentagem de sementes danificadas e de sementes com presença de sarcotesta. O restante das sementes foi colocado sobre uma tela e deixado para secar à sombra em ambiente protegido do sol e ventilado durante $24 \mathrm{~h}$.

O teste de germinação foi realizado com quatro repetições com 30 sementes semeadas em areia esterilizada ( $120^{\circ} \mathrm{C}$ por $2 \mathrm{~h}$ ), em badejas de poliestireno espandido suspensas cerca de $1 \mathrm{~m}$ do solo, por meio de estrado de madeira, em casa de vegetação.

A contagem de plântulas emersas foi realizada diariamente até 30 dias da semeadura, contabilizandose aquelas com os cotilédones abertos. Foram calculados a percentagem de germinação e o Índice de Velocidade de Emergência (IVE), utilizando-se o método descrito por Maguire (1962).
Ao final do teste, efetuou-se o corte das plântulas na região do colo e mensurou o comprimento da parte aérea das plântulas de cada tratamento com régua graduada.

Utilizou-se o Delineamento Inteiramente Casualizado (DIC), cujos resultados das variáveis analisadas foram submetidos à análise de variância e as médias, comparadas pelo teste de Tukey (5\%).

\section{RESULTADOS E DISCUSSÃO}

Os tratamentos apresentaram diferenças quanto à eficiência de remoção da sarcotesta (Tabela 1). As sementes submetidas aos tratamentos químico e ao despolpador não apresentaram qualquer sinal de dano, porém a eficiência desses métodos quanto à remoção da sarcotesta foi mais baixa que os demais, 85 e $66 \%$ de sementes com sarcotesta, respectivamente. Os tratamentos de fricção sobre peneira com adição de areia ou de cal apresentaram pequena porcentagem de sementes quebradas e máxima remoção da sarcotesta.

A remoção da sarcotesta com liquidificador, embora eficiente, apresentou alta porcentagem de sementes danificadas (31\%), mesmo estando as hélices revestidas com borracha (garrote). Os danos foram provocados, provavelmente, pelo choque das sementes contra a hélice e, ou, a parede do copo do liquidificador.

A porcentagem e velocidade de germinação, bem como o comprimento da parte aérea das plântulas, foram influenciados pelos métodos de remoção da sarcotesta (Tabela 2 ).

A remoção da sarcotesta de sementes de jaracatiá pelo método de fricção sobre peneira com adição de areia proporcionou a maior porcentagem e velocidade de germinação, além de maior crescimento da parte aéra das plântulas em comparação com os demais tratamentos avaliados, embora não tenha diferido do método em que foi utilizado cal, quanto a germinação e comprimento da parte aérea (Figura 1).

Tabela 1 - Eficiência dos diferentes métodos de remoção da sarcotesta de sementes de jaracatiá. Table 1 - Efficiency of the different methods of the sarcotesta removal of jaracatia seeds.

\begin{tabular}{cccc}
\hline Tratamento & Sementesdanificadas (\%) & Sementes com sarcotesta (\%) & Sementes sem sarcotesta (\%) \\
\hline Peneira+areia & 8 & 0 & 92 \\
Peneira+cal & 10 & 0 & 90 \\
Liquidificador & 31 & 11 & 58 \\
Despolpador & 0 & 66 & 34 \\
Remoção química & 0 & 85 & 15 \\
\hline
\end{tabular}


Tabela 2 - Germinação, índice de velocidade de emergência e comprimento da parte aérea, obtidos em sementes de jaracatiá submetidas a diferentes métodos de remoção da sarcotesta.

Table 2 - Germination, Index of Speed of Emergency and shoot length, in jaracatiá seeds submitted to different methods of the sarcotesta removal.

\begin{tabular}{cccc}
\hline Tratamento & Germinação (\%) & IVE & Comp. p. aérea (cm) \\
\hline Testemunha & $39 \mathrm{~b}$ & $5,23 \mathrm{~d}$ & $4,83 \mathrm{~d}$ \\
Peneira+areia & $63 \mathrm{a}$ & $11,13 \mathrm{a}$ & 9,41 a \\
Peneira+cal & $52 \mathrm{ab}$ & $8,64 \mathrm{~b}$ & 7,82 abc \\
Liquidificador & $43 \mathrm{~b}$ & $7,19 \mathrm{bcd}$ & $6,54 \mathrm{~cd}$ \\
Despolpador & $39 \mathrm{~b}$ & $5,89 \mathrm{~cd}$ & 6,75 bc \\
Químico* & $48 \mathrm{~b}$ & $7,88 \mathrm{bc}$ & 8,41 ab \\
CV $(\%)$ & 14,7 & 2,08 & 1,86 \\
\hline
\end{tabular}

Médias seguidas pela mesma letra não diferem entre si, pelo teste de Tukey a 5\%de probabilidade.

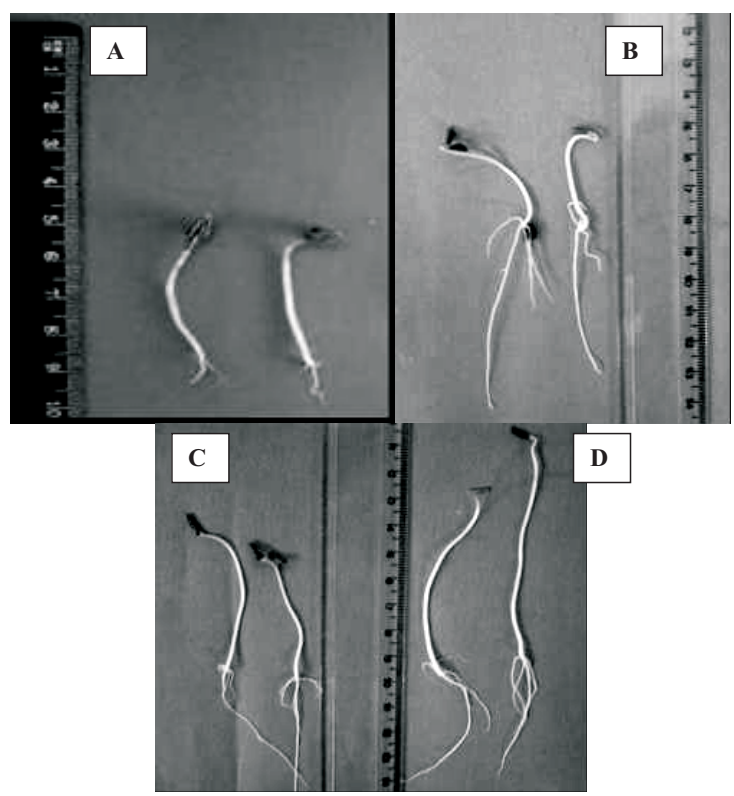

Figura 1 - Plântulas de jaracatiá (Jaracatia spinosa (Aubl.) A. DC) oriundas de sementes com sarcotesta (A) e de sementes submetidas à remoção da sarcotesta utilizando liquidificador (B), solução química (C) e friç̧ão sobre peneira com adição de areia (D), 32 dias após a semeadura.

Figure 1 - Jaracatiá plantules (Jaracatia spinosa (Aubl.) A. DC): originating from of seeds with sarcotesta (A) and originating from of seeds submitted to the sarcotesta removal with blender method (B), with chemical solution and for friction on sieve with addition of sand (D), 32 days after the sowing.

Quanto ao vigor, avaliado pela velocidade de germinação e crescimento de plântulas, os piores resultados foram obtidos nos tratamentos com a utilização do despolpador e liquidificador, semelhante à testemunha (sementes com sarcotesta) (Figura 1). Resultados semelhantes foram obtidos por Schmildt et al. (1993) para sementes de mamão, verificando que a manutenção da sarcotesta resultou na redução da germinação, e a remoção dessa estrutura mediante fricção com areia em peneira resultou nos maiores valores de germinação do trabalho. Para sementes de calabura (Muntigia calabura L.), Lopes et al. (2002) verificaram que a manutenção da mucilagem inibiu o processo germinativo, e os tratamentos com $\mathrm{CaO}$ melhorou a capacidade germinativa dos lotes.

Os resultados mais favoráveis à germinação e vigor das plântulas foram obtidos com os tratamentos de fricção sobre peneira com adição de areia e cal, estando, provavelmente, relacionados com o grau de eficiência na remoção da sarcotesta associados ao menor dano mecânico às sementes, visto que tais métodos proporcionaram a maior porcentagem de sementes sem sarcotesta e poucas sementes danificadas (Tabelas 1 e 2).

A presença da sarcotesta prejudicou a germinação das sementes e o desenvolvimento das plântulas, confirmando a possível presença de substâncias inibidoras da germinação na sarcotesta. Tokuhisa et al. (2007) relataram que uma das causas da dormência em sementes de mamão pode ser atribuída à presença de fenóis na sarcotesta e, principalmente, na esclerotesta. Segundo Taylorson e Hendricks (1977), os compostos fenólicos presentes no envoltório da semente retém o oxigênio, o que poderia limitar o suprimento deste para o embrião durante a germinação, acarretando dormência.

Chow e Lin (1991) afirmaram que os compostos fenólicos atuam inibindo reações ligadas ao processo de germinação das sementes de mamão, sendo recomendada a secagem das sementes a $40^{\circ} \mathrm{C}$, e isso 
proporcionará a diminuição da ação desses compostos, aumentando significativamente a germinação em relação às sementes frescas, recém-extraídas do fruto.

Outro fator observado foi que as sementes com sarcotesta foram mais atacadas por fungos, a sarcotesta serviu como meio para a propagação desses microrganismos, atrapalhando o processo germinativo e desenvolvimento das plântulas, de modo semelhante ao verificado por Martins et al. (2004) em sementes com polpa de palmiteiro-jussara.

A remoção da sarcotesta com liquidificador e com despolpador são métodos mais rápidos e práticos, porém não apresentaram resultados satisfatórios para as variáveis estudadas.

O liquidificador provocou a quebra de muitas sementes, e mesmo as sementes não quebradas, utilizadas no teste de germinação, tiveram sua germinação comprometida, provavelmente como resultado de danos internos sofridos pelas sementes (Tabelas 1 e 2). Resultados similares foram obtidos na remoção da sarcotesta de sementes de mamão (SCHMILDT, 1993) e na remoção do arilo de sementes de maracujá (MARTINS et al., 2006).

A solução química não proporcionou eficiência na remoção da sarcotesta; além disso, o custo e pouca praticidade desse método, com o manuseio de reagentes que podem apresentar perigo à saúde humana, dificultam sua utilização, principalmente em larga escala.

\section{CONCLUSÕES}

Diante dos resultados, conclui-se que o método mais favorável à remoção da sarcotesta e promoção da germinação das sementes de jaracatiá é a fricção sobre peneira com adição de areia.

\section{REFERÊNCIAS}

ARAUJO, E. F. et al. Efeito da danificação mecânica e da remoção manual do pergaminho sobre a emergência das plântulas de Coffea arábica L. Revista Brasileira de Armazenamento, v. Especial Café, n.8, p.1-5, 2004.

BUENO, B. et al. Germinabilidade de sementes de Jaracatia spinosa (AUBL.) A. DC. na presença ou ausência da sarcotesta. In: REUNIÃO ANUAL DA SBPC, 57., 2005, Fortaleza. Anais...

Fortaleza: 2005
CANDIANE, G.; GALETTI, M.; CARDOSO, V. J. M. Seed germination and removal of Mmichelia champaca 1.(Magnoliaceae) in eucalypt stands: the influence of the aril. Revista Árvore, v.28, n.3, p.327-332, 2004.

CHOW, Y. J.; LIN, C. H. p-Hydroxibenzoic acid the major phenolic germination inhibitor of papaya seed. Seed Science and Technology, v.19, p167-174, 1991.

CONEGLIAN, R. C. C. et al. Efeitos de métodos de extração e de ácido giberélico na qualidade de sementes de maracujá-doce (Passiflora alata Dryander). Revista Brasileira de Fruticultura, v.22, n.3, p.463-467, 2000.

CORREIA, M. P. Dicionário das plantas úteis do Brasil e das exóticas cultivadas. Brasília: IBDF, 1984.v.2.

DIAS, M. C. L. L.; BARROS, A. S. R. Avaliação de métodos de remoção da mucilagem de sementes de café (Coffea arábica L.). Revista Brasileira de Sementes, v.15, n.2, p.191-195, 1993.

EDER-SILVA, E.; FELIX, L. P.; BRUNO, R. L. A. Citogenética de algumas espécies frutíferas nativas do nordeste do Brasil. Revista Brasileira de Fruticultura, v.29, n.1, p.110-114, 2007

FERREIRA, G. et al. Efeito de arilo na germinação de sementes de passiflora alata curtis em diferentes substratos e submetidas a tratamentos com giberelina. Revista Brasileira de Fruticultura, v.27, n.2, p.277-280, 2005.

GHERARDI, E.; VALIO, I. F. M. Occurrence of promoting and inhibitory substances in the seed arils of Carica papaya L. Journal of Horticultural Science, v.51, p.1-14, 1976.

LOPES, J. C.; PEREIRA, M. D.; MARTINS-FILHO, S. Germinação de sementes de calabura ( Muntigia calabura L.). Revista Brasileira de Sementes, v.24, n.1, p.59-66, 2002.

LORENZI, H. Árvores brasileiras: manual de identificação de plantas arbóreas nativas do Brasil. Nova Odessa: Plantarum, 2002. v.1.

Revista Árvore, Viçosa-MG, v.35, n.1, p.91-96, 2011 
MAGUIRE, J. D. Speed of germination aid in selection and evaluation for seedling emergence and vigor. Crop Science, v.2, p.176-177, 1962.

MACIEL, A. S.; BORGES, E. E. L.; BORGES, R. C. G. Determinação da presença de fenóis em sementes de espécies florestais e sua relação com inibidores de germinação. Revista Brasileira de Sementes, v.14, n.1, p.1-8, 1992.

MARTINS, C. C. et al. Temporary storage of jussara palm seeds: effects of time, temperature and pulp on germination and vigor. Horticultura Brasileira, v.22, n.2, p.271-276, 2004.

MARTINS, M. R. et al. Influência de diferentes métodos de remoção do arilo na germinação de sementes de maracujazeiro-amarelo (Passiflora edulis Sims f. flavicarpa deg.). Revista da FZVA, v.13, n.2, p.28-38, 2006.

MARIN, J. L. D.; GOMES, J. A.; SALGADO, J. S. Recomendação para a cultura do mamoeiro cv. Solo do Estado do Espírito Santo. 3.ed.., Vitória: 1987.64p.

MEDINA, J. C. Cultura. In: INSTITUTO DE TECNOLOGIA DE ALIMENTOS. Mamão. 2ะed. Campinas: Instituto Campineiro de Ensino Agrícola, 1989. p.1-177.

MELO, A. L. Efeitos da retirada do arilo e do armazenamento e aspectos morfológicos de sementes do maracujazeiro (Passiflora spp.). 1996. 52f. Dissertação (Mestrado em Produção e Tecnologia de Sementes) - Faculdade de Ciências Agrárias e Veterinárias, Universidade Estadual Paulista, Jaboticabal, 1996.

PAOLI, A. A. S. Morfologia, anatomia e aspectos da germinação de Jacaratia spinosa (AUBL.) A.DC. (Caricacea). 1986. Tese. (Doutorado em Ciências Biológicas) - Instituto de Biociências de Rio Claro. Universidade Estadual Paulista Júlio de Mesquita Filho, Rio Claro, 1986.
PEREIRA, R. S. et al. Emergência de plântulas de Copaifera langsdorffii Desf. Revista

Brasileira de Biociências, v.5, supl. 2, p.1005-1007, 2007.

PEREIRA, R. S.; SANTANA, D. G.; RANA, M. A. Emergência de plântulas oriundas de sementes recémcolhidas e armazenadas de Copaifera langsdorffii Desf. (Caesalpinioideae), triângulo mineiro, brasil. Revista Árvore, v.33, n.4, p.643-652, 2009.

REYES, M. N.; PÉREZ, A.; CUEVAS, J. Detecting endogenous growth regulators on the sarcotesta, sclerotesta, endosperm and embryo by paper chromatography on fresh and old seeds of two Papaya’s varieties. Journal Agriculture University of Puerto Rico, Porto Rico, v.64, n.2, p.167-172, 1980.

SALES, J. F. et al. Efeito da aplicação exógena de celulase na germinação de sementes de cafeeiro (Coffea arabica L.). In: SIMPÓSIO DE PESQUISA DOS CAFÉS DO BRASIL, 2., 2001, Vitória.

Resumos. Vitória: 2001. p.1714-1719.

SCHMILDT, E. R. et al. Comparação de métodos físicos de remoção da sarcotesta e de métodos de secagem de mamoeiro (Carica_papaya L.).

Revista Brasileira de Sementes, v.15, n.2, p.147-151, 1993.

TAYLORSON, R. B.; HENDRICKS, S. B. Dormancy in seeds. Annual Review of Plant Physiology, v.28, p331-354, 1977.

TOKUHISA, D. et al. Compostos fenólicos inibidores da germinação em sementes de mamão (Carica papaya L.) Revista Brasileira de Sementes, v.29, n.3, p.180-188, 2007.

VILELA, N. A. Efeito do arilo na germinação de sementes de Copaifera langsdorffii Desf. 1993. 14f. Monografia (Curso de Ciências Biológicas) - Instituto de Ciências Biológicas, Universidade de Alfenas, Alfenas, 1993. 